\title{
Diplomacia e Estado na primeira modernidade
}

\section{Diplomacy and State in Early Modern Times}

\author{
Peter Johann Mainka*
}

\section{RESUMo}

Na virada para os Tempos Modernos, os contatos entre os Estados pré-modernos nascentes começaram a aumentar. Representações diplomáticas esporádicas e específicas tornaram-se permanentes e gerais. A Itália renascentista deu impulsos importantes ao desenvolvimento da diplomacia moderna na prática, logo seguida pelas grandes monarquias ou dinastias. Cada um dos Estados e seus diplomatas procurou seu posicionamento específico no sistema dos Estados europeus, que estava em processo de consolidação. O Congresso de Vestfália contribuiu muito para se estabelecer e ajustar esse sistema frágil de Estados europeus, embasado nos princípios de igualdade e soberania, mas também de diferença e hierarquia. Com base numa bibliografia específica e atual, este artigo investiga o período da formação da diplomacia moderna no contexto das transformações da primeira modernidade.

Palavras-chave: Diplomacia moderna; Relações internacionais; Estado (pré-) moderno; Congresso de Vestfália.

\begin{abstract}
During the transition period towards the Modern Times, the relationship between the evolving pre-modern States started to expand. Sporadic and specific diplomatic representations became permanent and general. Italy, during the Renaissance, gave important incentives towards the development of modern diplomacy, later followed by other important monarchies and dynasties. Each State and their diplomats pursued a specific position within the system of European States, which was in formation at the time. The Congress of Westphalia contributed a lot to the establishment and adjustment of the fragile system of European States, based on the principles of equity and sovereignty, but also on difference and hierarchy. Grounded upon a current and specific bibliography, this article investigates the formation period of modern diplomacy in the context of the transformations of the Early Modern Times.

Keywords: Modern diplomacy; International relations; (Pre) Modern State; Congress of Westphalia.
\end{abstract}

\footnotetext{
* Universidade de Würzburgo, Würzburgo, Alemanha. peter.mainka@uni-wuerzburg.de <https:// orcid.org/0000-0003-4921-4221>
} 


\section{INTRODUÇÃO}

O Estado moderno, racional e institucionalizado, é definido, em princípio, por três elementos, segundo Georg Jellinek (1851-1912): por um determinado território marcado por fronteiras mais ou menos exatas, por um determinado povo que habita esse território e pelo poder soberano do Estado exercido nesse território (Jellinek, 1905). Partindo dos resultados da Revolução Americana (1776) e sobretudo da Revolução Francesa (1789), com base nas ideias do nacionalismo e do liberalismo, em parceria com a sociedade burguesa e com a economia capitalista, o Estado Nacional moderno chegou à sua forma completa e acabada somente no século XIX. Esse modelo do Estado tornou-se (1) objeto central de discussões e reflexões teóricas, realizadas por pensadores de áreas variadas - como Georg Wilhelm Friedrich Hegel (1770-1831), Alexis de Tocqueville (1805-1859), John Stuart Mill (1806-1873), Karl Marx (1818-1883) e Friedrich Engels (1820-1895) - e (2) modelo e protótipo das pesquisas históricas, desenvolvidas nos séculos XIX e XX pelos historiadores do historicismo. Nesse sentido, foi explorado sobretudo por prussianos muito influentes na historiografia daquela época, como Leopold von Ranke (1795-1886), Johann Gustav Droysen (1808-1884) ou Friedrich Meinecke (1862-1954). Outro intelectual que se dedicou a questões do Estado e do poder foi Max Weber (1864-1920), que descreveu o Estado moderno, racional e burocrático com lucidez e exatidão, determinando as representações e os ideias de gerações de doutos nas ciências humanas e sociais que se ocuparam desse tema.

O caráter do Estado moderno desse tipo, que se manifestou sobretudo a partir do século XIX, distingue-se muito, porém, do Estado da época moderna que estava, entre os séculos XV e XVIII, em processo de formação. Essa fase formativa da modernidade era caracterizada, segundo Max Weber, pelos processos fundamentais de racionalização, burocratização, institucionalização, profissionalização e desencantamento do mundo ocidental (Schluchter, 2013 [2009]). Trata-se de processos transformadores que se manifestaram em quase todas as áreas da vida humana - e também no Estado e na diplomacia. Os processos de formação tiveram pleno andamento, sem que os destinos fossem definidos ou prefigurados: nem a distribuição do poder entre monarca/príncipe e as elites influentes na direção do Estado, nem a competência exclusiva de representar os interesses do Estado no exterior eram determinadas definitivamente. Os poderes do Estado ainda não eram monopolizados e organizados de modo uniforme, centralizado e hierárquico - características essenciais do Es- 
tado moderno, como indicam muitos manuais de história, sem diferenciar as fases diversas da modernidade (Marques; Berutti; Faria; 2017, pp. 54-55).

O Estado da História Moderna - ou seja da Early Modern History, em inglês, da Frühe Neuzeit, em alemão ou da Histoire Moderne, em francês - era diferente tanto do Estado medieval quanto do Estado contemporâneo. A época moderna apresentou-se como verdadeiro laboratório da modernização e da transformação. Enquanto o Estado medieval exerceu seu poder sobre pessoas ou grupos de pessoas - mesmo que os direitos feudais já houvessem começado a se territorializar, tornando-se aos poucos fronteiras territoriais (Brunner, 1984 [1939], pp. 385-394) -, o Estado moderno clássico definiu-se, como mencionado, pelos três elementos constitutivos: (1) território, (2) povo e (3) poder soberano. Para distinguirmos esse Estado em transição dos dois outros tipos propomos o termo "Estado (pré-)moderno".

O Estado pré-moderno não era tão organizado e hierarquizado, institucionalizado e centralizado, nem tão soberano, absoluto e poderoso como sugeriu o modelo tradicional do Estado moderno completo e acabado. $\mathrm{Na}$ área da política externa, as competências também não eram definidas exatamente, nem reservadas de forma exclusiva ao monarca/príncipe e ao Estado. A representação do Estado nas relações internacionais não ficou restrita ao governo soberano naquele tempo, quando os diferentes atores políticos (monarca, príncipe - corporações, parlamentos, elites) ainda concorreram pelo poder no Estado. Os detentores coroados do Poder Executivo não foram os únicos no Estado pré-moderno que definiram ou pretenderam definir a política externa e organizá-la.

Houve concorrentes legítimos pelo exercício desse direito, como (1) as corporações imperiais, que estabeleceram uma aliança com a França contra o imperador Carlos V (1551/1552) - ou reclamaram, durante a Guerra dos Trinta Anos e nas negociações da Paz de Vestfália, o pleno direito de atuar, sem quaisquer limites, no palco internacional -; (2) as corporações territoriais, como no caso das corporações boêmias, que estabeleceram, no início da Guerra dos Trinta Anos (1618), alianças políticas e militares com as corporações dos Estados vizinhos da Moravia, da Silésia e da Áustria, dirigidas contra a dinastia dos Habsburgos; ou (3) o parlamento da Inglaterra em vários momentos na história medieval e moderna, sobretudo nos acontecimentos da Revolução Gloriosa (1688/1689). Nos Estados pré-modernos, até companhias comerciais exerciam, às vezes, competências da política externa. Podemos citar os exemplos: (1) da companhia comercial dos Welser, localizada na Cidade Imperial de Augsburgo, que atuava na Venezuela na primeira metade do século XVI, ou (2) das Compa- 
nhias Holandesas das Îndias Orientais e das Índias Ocidentais, no seculo XVII, empresas comerciais equipadas com direitos estatais.

Somente a partir dos Tratados de Paz de Vestfália, a soberania dos Estados foi fortalecida, tornando-se um elemento importante na formação do Estado pré-moderno e moderno. Em nome dos respectivos soberanos, sejam monárquicos, sejam republicanos, um conselho governamental ou um ministro ou secretário de Estado organizava e dirigia, exclusivamente, a política externa de um Estado. Ao lado dos outros ministérios responsáveis pelas questões financeiras, militares, jurídicas e, mais tarde, econômicas (comerciais), a competência da política externa foi concedida a um setor cada vez mais qualificado, especializado e profissionalizado. Esse protótipo desenvolvido do Estado moderno burocrático é muito distinto das manifestações históricas do Estado pré-moderno, entre os séculos XV e XVIII.

Quanto às estruturas relativas à política externa, o governo do Estado pré-moderno não dispôs nem de um aparato burocrático-administrativo central, nem de um corpo diplomático competente para o estrangeiro, cuja formação gradual está no centro deste artigo. No exemplo específico da diplomacia moderna (Anderson, 1993) pode-se verificar, como num espelho, todas as tendências gerais dessa época: processos variados de racionalização, institucionalização e profissionalização que resultaram, sobretudo a partir da reorganização da política europeia pelos Tratados de Paz da Vestfália em 1648, no fortalecimento do Poder Executivo e no crescimento do Estado (pré-)moderno.

Com consciência de toda a crítica aos conceitos tradicionais da historiografia considerados antiquados e eurocênticos (Ballestrin, 2013; Santos; Meneses, 2009), mas também tendo convicção da necessidade de se manter o uso pragmático deles, pretende-se neste artigo delinear, em linhas gerais, a história da diplomacia moderna da Idade Média tardia até o fim da Guerra dos Trinta Anos (1648); período em que os fundamentos estruturantes do mundo moderno até os dias de hoje foram lançados. Com base na historiografia atual e especializada, descrevemos o percurso da diplomacia moderna, destacando os pontos variados de partida, as tendências gerais e os acontecimentos significativos.

A diplomacia moderna fez parte integral do conjunto das outras transformações profundas que contribuíram para a configuração cada vez mais eficiente e racional do Estado: o processo de confessionalização na área da religião, a transferência, da igreja para os Estados nascentes, das responsabilidades pela educação (escolas e universidades) e pela assistência a pobres, a nova política ativa e intervencionista do Estado na economia (mercantilismo) etc. 


\section{OS PRIMÓRDIOS DA DIPLOMACIA MODERNA}

Já na Antiguidade Clássica (Dignas; Winter, 2007) e na Idade Média (Lima, 2015) existiam relações entre diferentes povos ou tribos, impérios ou Estados, geralmente por meio de legações ou missões diplomáticas especiais que foram enviadas para resolverem questões específicas. Porém, a diplomacia moderna e regular, exercida cada vez mais por profissionais qualificados e realizada entre os Estados em pleno processo de formação, é um fenômeno distinto:

[...] uma invenção dos Tempos Modernos europeus. Ela [a diplomacia moderna] era uma consequência da formação de Estados pré-modernos e, por conseguinte, da coexistência de Estados particulares, cada qual deles exigindo direitos iguais, que tinham que entrar em relação entre si. Devido a essa necessidade nasceu a diplomacia, primeiro a pré-moderna, depois a moderna, como representação diplomática permanente de um Estado em todos os outros Estados, considerados por ele importantes (Schilling, 2007, p. 120).

As características significantes da diplomacia moderna (Jucker; Kintzinger; Schwinges, 2011) são, segundo Heinz Schilling, a permanência e a ubiquidade das representações diplomáticas, dos códigos de comportamento e dos modelos e procedimentos de atuação, formalizados como um corpo de diplomatas qualificados e instruídos (Schilling, 2007, p. 120s.)

Na Idade Média (Jaspert; Kolditz, 2014), as legações diplomáticas foram, em sua grande maioria, legações específicas encarregadas de uma certa tarefa ou por um período determinado, sobretudo para entrar em contato com soberanos fora da cristandade ocidental. O imperador Carlos Magno (768-814) enviou, por exemplo, duas legações ao califa abássida Harune Arraxide (763809) em Bagdá, pretendendo dar proteção aos cristãos nos países islâmicos (Bieberstein, 1993, p. 165). Mais de 400 anos mais tarde, Frederico II (11941250), rei da Sicília e imperador, entrou em negociações diretas com o sultão Al-Kamil Muhammad al-Malik (1180-1238) e conseguiu, apesar de circunstâncias adversas, estabelecer o Acordo de Paz de Jaffa (1229), que garantiu aos cristãos a posse de Jerusalém e alguns outros lugares (Mamoun, 2008).

Nos séculos XV e XVI, as legações tornaram-se mais frequentes nas relações externas entre os poderes cristãos (Zey, 2008). A República de Veneza (Gleason, 1993) e a cúria do papado (Koller; 2012) deram fortes impulsos neste sentido. Em seguida, foram as grandes potências europeias, nomeada- 
mente a Espanha e depois a França, que estabeleceram legações permanentes nas cortes, seja de seus aliados, seja de seus inimigos (Cardim, 2004).

\section{A ItÁlia RENASCENTISTA}

A Itália renascentista foi a região mais desenvolvida na Europa nas perspectivas econômica e política, e foi o local no qual várias inovações se manifestaram de modo mais notável - além da política e da economia, na educação, na cultura, na ciência, na tecnologia e também na diplomacia (Azzolini; Lazzarini, 2017). Localizada no Mediterrâneo - que era, desde a Antiguidade, uma plataforma giratória de ideias, pessoas e mercadorias, entre Europa, África e Ásia, entre o ocidente e o oriente -, a Península Apenina foi predestinada como elo entre as fronteiras culturais e estatais (Cardim, 2004).

Na Itália, na segunda metade do século XV - entre a Paz de Lodi (1454) e a invasão francesa ao reino de Nápoles em 1494 -, estabeleceu-se um equilíbrio entre as cidades-estados e os Estados (o ducado de Milão, as repúblicas de Florença e Veneza, os Estados Pontifícios e o reino de Nápoles) que garantiu um clima muito favorável e fecundo para transformações modernizantes e inovadoras (Frigo, 2000). Daí provieram impulsos fortes à formação do Estado pré-moderno e do capitalismo pré-moderno, à reflexão filosófica e intelectual, à ampliação do horizonte científico e geográfico do mundo. Por tudo isso, a Itália, como região mais avançada na virada da Idade Média para os Tempos Modernos, tornou-se o alvo das cobiças de outros Estados, como da França, em 1494. Isso acabou com o equilíbrio na Itália e iniciou um processo agitado de reestruturação do sistema de Estados, que, por sua vez, intensificou o processo de formação do Estado pré-moderno institucional.

Enquanto esse equilíbrio era muito frágil, os membros menos poderosos, como a Veneza, precisavam de informações sobre as intenções das cidades-estados rivais, a fim de se prevenirem e tomarem precauções com antecedência (Bueno; Freire; Oliveira, 2017, p. 628). Além disso, a República de São Marcos teve relações políticas e sobretudo comerciais com outros Estados europeus e também com Constantinopla, Moscou e Pérsia. A diplomacia veneziana apresentou, ainda na Idade Média, elementos de institucionalização. Os enviados tinham que entregar, dentro de um prazo de 14 dias, um relato ao Arquivo do Estado, que guarda essas relações a partir de 1530, quase sem lacunas (Münkler; Münkler, 2005 [2000], p. 72). Esses relatos (relazioni) informaram o governo veneziano sobre os monarcas e os governos dos Estados visitados, sua política interna e externa, seus planos e projetos e seus problemas 
e empecilhos. Com base nessas informações valiosas, a diplomacia veneziana foi uma das mais avançadas nos séculos XVI e XVII, como mostra a atuação de Alvise Contarini (1597-1653) como um dos dois mediadores no Congresso da Paz de Vestfália (Wilson, 2017 [2009], pp. 777-859).

A coleção regular de dados e informações, a observação do que de importante e interessante aconteceu no país anfitrião e a transmissão rápida e segura desses dados tornaram-se as atividades principais dos diplomatas modernos (Kohler, 2008, p. 34). Por razões de segurança, as informações foram codificadas ou enviadas, simultaneamente, por caminhos diferentes (Mulsow; Rous, 2015). Seguindo o exemplo da República de Veneza, outros governos começaram a colecionar os dados em seus arquivos, registrá-los e disponibilizá-los aos dirigentes responsáveis (Reinhard, 2002 [1999], p. 373).

A cúria papal, como órgão central da igreja católica que pretendeu atuar no âmbito global, foi um outro ponto de partida que contribuiu muito para a institucionalização da diplomacia moderna (Fletcher, 2015; Carletti, 2010, p. 38s.). O papa, representando "one body and two souls" (Prodi, 1982). Como Vigário de Cristo e chefe da igreja católica, exigiu, por um lado, o controle de todo o mundo e, por outro lado, atuou como príncipe territorial e secular, defendendo os interesses específicos dos Estados pontifícios (Cardim, 2004). Ao lado do papado, sobretudo os representantes da Casa d'Áustria defenderam ideias de uma monarquia ou hegemonia universal: o imperador Carlos V, na primeira metade do século XVI, e seu filho Filipe II, rei espanhol, na segunda metade do século XVI (Cardim, 2004).

A Santa Sé havia acumulado, a partir dos tempos medievais, muita experiência na área das relações internacionais. A partir da segunda metade do século XV, a cúria começou a enviar legados permanentes, chamados núncios (Cardim, 2004), a outros Estados europeus: por volta de 1450 para a Espanha, em 1500 para Veneza, em 1514 para o Sacro Império Romano-Germânico e, até 1523, também para França e Portugal (Kohler, 2008, p. 31s.). Esse sistema de nunciaturas foi ampliado e aperfeiçoado pelo papa Gregório XIII (15021585, papa a partir de 1572), englobando toda a Europa católica (Koller; 2012). Ao mesmo tempo, a organização burocrática da política externa foi reformada e profissionalizada. Enquanto normas foram estabelecidas em relação à qualificação, formação, competência e atuação dos núncios, o secretário de Estado papal, responsável pela política externa da cúria, tornou-se verdadeiramente o ministério central, competente e eficiente, que coordenava - a partir de 1644 sob a direção exclusiva de um cardeal - todas as atividades externas do papado (Schilling, 2007, p. 124s.). 


\section{AS REPRESENTAÇõES DIPLOMÁTICAS PERMANENTES}

Ao lado da cúria papal e de Veneza destacaram-se, nas relações internacionais da virada da Idade Média para os Tempos Modernos, as coroas espanholas de Castela e Aragão. Na política externa dos reis católicos, nomeadamente de Fernando II de Aragão (1452-1516), houve fortes interesses na Itália (Dandelet; Marino, 2007), que se opuseram aos da França. A Espanha começou a enviar emissários a vários Estados europeus no último quarto do século XV, e estes estabeleceram residência permanente nesses locais. Dessa forma, enviados permanentes espanhóis atuaram: a partir de 1475 em Roma, a partir de 1487 em Londres, a partir de 1494 em Veneza, a partir de 1495 em Portugal, a partir de 1499 na França e a partir de 1513 em Gênova. Nesse sentido, todo o corpo diplomático dos reis católicos "foi marcado pela diversidade da origem territorial, da 'multinacionalidade'; isso perdurou também no tempo de seu sucessor Carlos V (1500-1558), que uniu o corpo diplomático espanhol com o corpo diplomático imperial, que proveio dos Países Baixos e do Sacro Império Romano-Germânico" (Kohler, 2008, p. 34; Ochoa Brun, 1991). O avô de Carlos V, o imperador Maximiliano I de Habsburgo (1459-1519) (Metzig, 2016), e os duques da Borgonha serviram-se, já no século XV, de enviados permanentes, enquanto a maioria dos outros Estados europeus seguiram essa estratégia somente mais tarde. A França (Autrand; Allain, 2007) tinha, em 1515, somente um diplomata desse tipo; em 1547, quando o rei francês Francisco I faleceu, havia dez deles. Até o início do século XVII estabeleceu-se, na Europa Central e na Ocidental, um sistema consolidado de diplomatas permanentes (Reinhard, 2002, p. 372).

Ao lado das representações diplomáticas permanentes, as legações específicas e extraordinárias não perderam sua importância (Hollegger, 2007), principalmente no Império Romano-Germânico, cuja diplomacia foi, em comparação com a Espanha ou a França, menos desenvolvida e profissionalizada. Os emissários do imperador, por exemplo, nem sempre dispuseram da proficiência exigida de línguas, nomeadamente do latim clássico, e das capacidades retóricas necessárias. O imperador Frederico III (1415-1493), casado com a princesa portuguesa Leonor (1434-1467), enviou, ao todo, 250 missões especiais a outros Estados (Heinemeyer, 2016).

A grande expansão da Dinastia Habsburgo aumentou a necessidade de comunicação dentro da Casa d'Áustria. Partindo dos territórios de origem, ou seja, dos territórios hereditários austríacos (österreichische Erblande), ampliados em 1493 pelo condado do Tirol, a dinastia dos Habsburgos (Mainka, 2019) 
conseguiu incorporar, sobretudo por meio de casamentos, uma série de outros territórios a seu domínio: os Países Baixos (1477), os reinos espanhóis de Castela e Aragão, com as possessões na Itália e no Novo Mundo (1516), e os reinos da Hungria e da Boêmia (1526); dominando, finalmente, um espaço extenso na Europa, do Oriente ao Ocidente e ao Sul, nas Américas e também na Ásia (Lynch, 1994). Para garantirem a comunicação entre os centros de poder na Europa, os Habsburgos deram início aos correios, sob encargo da família de Thurn e Taxis, que recebeu o monopólio de transportar as mensagens e cartas imperiais no Sacro Império Romano-Germânico, nos Países Baixos e nos reinos espanhóis (Behringer, 1990). O perfil dos diplomatas que atuavam a serviço da dinastia dos Habsburgos a partir de Maximiliano I foi internacional (Metzig, 2016). Na diplomacia dos imperadores, na primeira metade do século XVI, destacou-se o aristocrata Sigismund von Herberstein (1486-1566), ao qual foram confiadas 69 missões diplomáticas, entre elas: 30 à Hungria, 13 à Polônia e duas - as mais famosas - ao Grão-Principado de Moscou, em 1517 e 1526 (Kohler, 2008, p. 36s.).

Agentes comerciais e/ou pessoas privadas que haviam assumido missões específicas a serviço do Estado nos primórdios da diplomacia tornaram-se aos poucos enviados permanentes e residentes nos países anfitriões (Hollegger, 2007). Surgiram, em Veneza e na Espanha, regulamentações específicas para os serviços diplomáticos e seu financiamento. Os eclesiásticos que haviam participado frequentemente nas legações tradicionais foram substituídos, na diplomacia moderna, por aristocratas (Cardim, 2004), formados nas escolas de corte ou nas academias de cavaleiros, instruídos no comportamento cortês, com bons conhecimentos do latim e de outras línguas estrangeiras e comprometidos com as ideias do humanismo, sobretudo da retórica. Eles formaram na época moderna - como os oficiais - um grupo social transnacional, relacionado entre si (Schilling, 2007, p. 121s.).

"Um representante permanente pôde ser chamado Orator, Procurator, Commissarius, Secretarius, Nuntius, Deputatus, Legatus, Consiliarius, Ambassador ou combinar vários nomes" (Reinhard, 2002, p. 372). Os novos diplomatas encontraram-se numa situação complicada: considerados pelos anfitriões possíveis espiões, e pelos próprios soberanos possíveis traidores (Münkler; Münkler, 2005, p. 72s.). A situação dos diplomatas permaneceu precária e perigosa. Devido à falta de formas e práticas diplomáticas, aceitas e compartilhadas por todos os Estados, os enviados foram ameaçados de expulsão, perseguição ou até morte (Kohler, 2008, p. 40). Apesar da ideia de imunidade dos diplomatas (Reinhard, 2002, p. 374), desenvolvida, por exemplo, por 
Hugo Grócio em sua obra-prima, intitulada De jure belli ac pacis libri tres, de 1625 (Grotius, 2012 [1625]), a segurança dos enviados permaneceu instável na prática até o século XVIII, sobretudo em Estados como o Império Otomano e a Rússia (Schilling, 2007, p. 135).

Com a consolidação da diplomacia moderna, cresceu o número de manuais sobre como o enviado e representante ideal deveria se comportar, sobretudo no início do século XVII (Reinhard, 2002, p. 372s.). Apesar disso, a situação dos diplomatas permaneceu insegura e precária. Por muito tempo, não houve normas amplamente reconhecidas ou remunerações fixas e regulares - e as despesas de um diplomata eram enormes, pois ele tinha que representar, segundo as regras do cerimonial daquele tempo, o poder e o prestígio de seu soberano e Estado, por seu estilo de vida e comportamento público (Schilling, 2007, pp. 131-134). Os núncios papais foram os primeiros que receberam salários fixos, no fim do século XVI - contudo, nem sempre estes foram pagos de forma regular; a maioria dos diplomatas foi obrigada a se endividar - na expectativa de receber, pelo menos em sua despedida, um presente precioso do anfitrião (Reinhard, 2002, p. 374).

No sistema dos Estados nascentes, era da maior importância defender sua posição social na concorrência entre os Estados ou até conseguir ascender na hierarquia. Por essas razões, a rivalidade entre os diplomatas espanhóis e franceses foi muito acirrada. O título, exigido ou concedido por um soberano no tratamento, implicava direitos de precedência, privilégios e o seu reconhecimento ou não. O príncipe eleitor da Baviera, Maximiliano I (1573-1651) determinou a seus diplomatas no Congresso da Paz de Vestfália insistir no título de excelência, uma ordem que causou algum atraso nas negociações em Münster e Osnabrück: como os diplomatas bávaros não haviam conseguido de antemão a concessão desse título, não lhes foi permitido ir a reuniões ou encontros (Greindl, 2014). A questão de títulos complicou também a relação entre o imperador e o rei francês: o imperador Ferdinando III (1608-1657) se recusou, ainda em meados do século XVII, a conceder ao rei Sol da França, Luís XIV (1638-1715), o título de majesté royale (Reinhard, 2002, p. 373).

\section{INTENSIFICAÇÃO DOS CONTATOS DIPLOMÁTICOS}

Apesar da intensificação da diplomacia moderna, acompanhada por um número maior de tratados bilaterais e multilaterais, não houve uma pacificação da Itália ou uma consolidação geral das relações internacionais dentro do sistema nascente dos Estados europeus. No período da confessionalização, quan- 
do os organismos dos Estados começaram a crescer, aproveitando-se de suas igrejas, a política externa dos Estados pré-modernos confessionais orientou-se, a partir de meados do século XVI, geralmente nas fronteiras da religião, seja católica, seja protestante. Enquanto o papado seguiu rigorosamente essa diretriz, que limitou enormemente a atuação de seu diplomata Fabio Chigi (15991667) no Congresso da Paz de Vestfália, os Estados seculares fizeram exceções no caso de necessidades políticas ou comerciais, como a República de Veneza, que teve diplomatas residentes na Inglaterra e nos Países Baixos. Essa flexibilidade facilitou a atuação do diplomata veneziano no Congresso de Vestfália, autorizado a negociar com os representantes de todos os lados religiosos.

O embate dos interesses políticos antagônicos e das oposições religiosas, que resultou na Guerra dos Trinta Anos, contribuiu, de certa forma paradoxalmente, para ampliar o sistema da nova diplomacia. "A diplomacia deveu seu nascimento a uma consolidação da instabilidade de relações de Estados existentes somente na Europa” (Reinhard, 2002, p. 377). Relações internacionais regulares tornaram-se imprescindíveis em tempos de crise. "A era confessional trouxe, por isso, uma ampliação permanente e uma consolidação progressiva do sistema europeu de legações" (Schilling, 2007, p. 127). Enquanto na Europa Ocidental e Central os Estados mais importantes conseguiram estabelecer relações diplomáticas permanentes a partir das primeiras décadas do século XVII, os Estados nas periferias da Europa seguiram esse rumo somente na segunda metade do século XVII.

Intensificaram-se também os contatos diplomáticos com os poderes fora da Europa, sobretudo com o Império Otomano, que havia derrotado o Império Bizantino. A partir do fim do século XV, Estados europeus, sobretudo as Repúblicas comerciais italianas, enviaram legações a Constantinopla - legações específicas, esporádicas e geralmente informais. No contexto das lutas entre Carlos V e Francisco I, a França estabeleceu as primeiras alianças oficiais (1536 e 1543) com o sultão Suleimão (1494-1566) do Império Otomano, dirigidas contra o imperador Carlos V, que chamaram, de forma negativa, a atenção do público europeu (Greengrass, 2018 [2014], p. 328; Mainka, 2003, p. 207). Essas alianças tornaram-se escândalos políticos, pois a França saiu, com isso, da solidariedade tradicional dos Estados cristãos diante dos infiéis, e foram fortemente criticadas pelos Habsburgos, que, por sua vez, começaram, no contexto das disputas na Hungria, a estreitar suas relações com os turcos (Ziegler, 2004).

O número das representações diplomáticas de Estados europeus em Constantinopla aumentou significativamente na virada do século XVI para o século XVII. Legações diplomáticas foram enviadas também ao Marrocos. A 
rede das relações diplomáticas permanentes cresceu cada vez mais, independentemente das fronteiras religiosas e culturais existentes. Com isso, os diplomatas que praticavam uma religião diferente daquela predominante no país anfitrião receberam, aos poucos, o direito de realizar cultos religiosos privados nas instalações de sua residência, a exemplo dos representantes ingleses na Espanha, a partir de 1604 (Schilling, 2007, p. 135s.). Também eram frequentes problemas quando súditos do Estado anfitrião frequentavam esses cultos (Reinhard, 2002, p. 374).

Enquanto as repartições centrais da República de Veneza e da cúria papal foram as primeiras que passaram por uma reforma burocrática modernizante e inovadora, os Estados seculares da Europa demoraram mais tempo (Bély, 2008; Rodríguez, 2000). Mesmo que a França houvesse conseguido estabelecer - apesar da crise dinástica que afetou o país -, na segunda metade do século XVI, a rede mais ampla de legações diplomáticas na Europa, faltava uma reorganização da repartição central da política externa da França. Essas reformas institucionais foram iniciadas, mais tarde, pelo cardeal Richelieu (1585-1642) e resultaram, a partir de 1626, num órgão central, que coordenava, quase como um Ministério das Relações Exteriores, a política externa do país (Moita, 2006).

A monarquia hispânica representou, na Europa do século XVI, o poder mais forte, exercendo influência notável nas questões políticas, religiosas e diplomáticas (Cardim, 2004). No início do século XVII, a França começou a aumentar seu poder e a assumir a hegemonia política e diplomática na Europa, como se manifestou nitidamente no Congresso da Paz de Vestfália e, ainda mais, no período posterior. A partir disso, "[...] a França tornou-se exemplar e paradigmática para a diplomacia dos Estados europeus - quanto às instituições e ao pessoal da mesma maneira como quanto ao direito, ao cerimonial e, não por último, quanto à língua e à terminologia" (Schilling, 2007, p. 131). A língua francesa tornou-se, desde a época de Luís XIV até o século XX, a língua geral da diplomacia.

\section{O Congresso da PAZ de Vestfália:}

\section{O LABORATÓRIO DA DIPLOMACIA MODERNA}

A formação do Estado pré-moderno, a partir da virada da Idade Média para os Tempos Modernos, foi acompanhada, entre muitos outros desenvolvimentos, pela formação da diplomacia moderna, sem que existisse um padrão geral, um modelo exemplar ou destinos claramente definidos. A implementa- 
ção de novas instituições diplomáticas, com diplomatas permanentes e residentes nos países anfitriões, realizou-se, na prática, sem plano ou instrução detalhada. As reformas protestantes haviam quebrado a união da cristandade ocidental e abalado, notavelmente, a reputação e o poder das duas potências universais: o papado e o império. Os avanços do Império Otomano muçulmano ameaçavam a Europa cristã, que havia acabado de reconquistar os últimos territórios árabes na Península Ibérica. E a expansão europeia para o Ultramar confrontava os Estados do Mundo Antigo com povos nativos e civilizações desconhecidas. Enquanto fronteiras religiosas e culturais prejudicaram e até impossibilitaram relações internacionais pacíficas, foi necessário encontrar novos meios e instrumentos de comunicação entre os Estados europeus e o mundo afora, independentes das religiões e culturas.

Partindo das reflexões antigas e medievais sobre o ius naturae e o ius gentium, a teoria política moderna se ocupou mais intensamente, no início dos Tempos Modernos, desses problemas complexos, como demonstram os autores da Escolástica espanhola tardia, sobretudo da Escola de Salamanca, Francisco de Vitória (1483-1546) e Francisco Suarez (1548-1617) (Vitória, 1995; 1997). Continuando as ideias deles, o neerlandês Hugo Grócio destacou, em 1625, em sua obra mais famosa, intitulada De jure belli ac pacis libri tres (Grotius, 2012), o direito como base firme e geral das relações internacionais pacíficas; ou seja, o Direito Internacional secular e neutro acima das religiões e culturas diferentes (Liziero, 2015).

Nem a prática da diplomacia moderna, nem a teoria do Direito Internacional moderno foram acabadas e concluídas quando começaram as negociações de paz nas duas cidades vizinhas de Münster e Osnabrück, visando o término da Guerra dos Trinta Anos (Wilson, 2017; Brandão, 2012) e da Guerra dos Oitenta Anos (Trillo; Echevarria Bacigalupe, 2008) entre a Coroa Espanhola e as Sete Províncias Unidas dos Países Baixos. O Congresso da Paz de Vestfália tornou-se, portanto, uma oportunidade experimental para que fossem reunidos os vários pontos isolados de partida nas relações diplomáticas, dinamizados os processos de desenvolvimento na diplomacia moderna, experimentados vários modelos de comportamento diplomático na prática e, finalmente, estabelecidos novos dispositivos práticos e teóricos nas relações internacionais.

O Congresso da Paz de Vestfália foi o primeiro grande congresso político-diplomático de dimensão europeia que reuniu enviados e representantes de quase todos os Estados pré-modernos em formação, seja como combatentes das lutas, seja como observadores e interessados. Faltaram somente: o Império Otomano, que fez parte do sistema europeu de Estados, naquele momento his- 
tórico, como rival e inimigo; a Rússia, que abriria a janela para a Europa somente sob o czar Pedro, o Grande (1672-1725); e a Inglaterra, abalada pela Guerra Civil. Destarte, o congresso de Vestfália tornou-se um dos maiores, mais complicados e mais longos da história, sem modelos similares precedentes.

Os grandes concílios da igreja católica do passado (May, 2016, pp. 75-79) - de Constança (1414-1418), Basileia (1431-1449) e Trento (1545-1563) - podem ser citados como exemplos, mas eles foram, apesar de seus impactos políticos, sobretudo encontros de líderes católicos (Cardim, 2004). Além disso, existe uma outra diferença: a reunião dos concílios costumava ser em plenário, enquanto os diplomatas em Münster e Osnabrück nunca se encontraram numa sessão plenária. Outros modelos possíveis de orientação para a prática diplomática no Congresso de Vestfália foram a corte do papa, conectada com a maioria dos Estados cristãos, e a dieta ou assembleia imperial (Mainka, 2019), que reuniu uma multidão de corporações de língua alemã, italiana, francesa, tcheca, dinamarquesa e flamenga, ou negociações de paz anteriores, como destaca Niels May (2016, pp. 76-99). Podemos lembrar as negociações de paz para pôr fim às lutas entre as Coroas Espanhola e Francesa em Cateau-Cambresis (1559) (Elliott, 2015) e em Vervins (1598), ou aquelas em Stettin (1570), que terminaram os conflitos entre a Suécia e Dinamarca, os rivais pelo poder no Mar Báltico (Greengrass, 2018, p. 610).

Devido ao seu tamanho extraordinário, à sua dimensão europeia e à sua importância, o Congresso de Vestfália tornou-se, por sua vez, o modelo exemplar na história moderna e contemporânea para a resolução de conflitos bélicos complexos e multilaterais de forma pacífica e o estabelecimento de novos fundamentos políticos que pudessem garantir ordem e segurança - pelo menos por um tempo determinado.

No ambiente internacional do Congresso da Paz de Vestfália, a diplomacia moderna passou por um processo de concentração, consolidação e amadurecimento. A prática diplomática sofreu uma padronização e uma uniformização quanto a procedimentos, modos e formas de estabelecer contato e relações entre Estados distintos e seus representantes. O Congresso de Vestfália tornou-se um verdadeiro laboratório da diplomacia moderna.

A partir da virada para os Tempos Modernos, como vimos antes, o número de legações diplomáticas aumentou consideravelmente, e também a qualidade delas: missões esporádicas e específicas tornaram-se missões permanentes e gerais. Cada um dos diplomatas residentes que representavam seu Estado e seu soberano precisavam procurar sua posição na hierarquia social da corte do Estado anfitrião, adequada à dignidade e ao poderio de seu Estado. Na li- 
teratura especializada do século XVII, discutiram-se as competências de cada cargo (embaixador, residente ou plenipotenciário) e questionou-se se o embaixador representava completamente a dignidade de seu soberano, sem se chegar, porém, a opiniões unânimes, aceitas por todos. Além da dignidade do soberano representado, também a qualidade do diplomata na hierarquia social da nobreza ou da igreja era relevante (May, 2016, pp. 53-73, 121-144).

Esse processo de negociação e diferenciação (Cardim, 2004) estava, na primeira metade do século XVII, em pleno andamento, e resultou, consequentemente, numa concorrência - às vezes violenta - com os representantes dos outros Estados. Um sistema fixo e acabado dos Estados europeus ainda não existia; somente a partir do Congresso de Vestfália, quando a posição alcançada na hierarquia social dos Estados era de maior importância, houve uma certa consolidação (Bély; Richefort, 2000). Estabeleceu-se um sistema coerente dos Estados e das relações entre eles, atribuindo-se a cada um seu lugar específico - um sistema consistente, mas não imutável, por ora consolidado, mas sempre frágil (Duchhardt, 1998).

Estes conflitos cerimoniais pela precedência - conflitos fundamentais e inerentes à sociedade estamental da época moderna - caracterizaram o Congresso de Vestfália desde o início. Enquanto os diplomatas do imperador reivindicaram para si uma precedência representativa, os diplomatas franceses defenderam sua equiparação, rejeitando qualquer precedência do imperador ou, pelo menos, tentando relativizá-la ou minimizá-la (May, 2016, pp. 115121). Quando, nas solenidades da abertura, os franceses recusaram-se a caminhar atrás dos representantes imperiais, encontrava-se, de forma criativa, uma solução salomônica: os dois grupos deveriam ir lado a lado em duas filas, os representantes do imperador do lado direito e os representantes do rei francês do lado esquerdo, abrindo-se aos dois a possibilidade de reclamar a vitória da disputa para si. Esse procedimento foi aplicado também em outras ocasiões durante o congresso, a fim de se resolver o embate de interesses opostos: sendo o lado direito considerado a posição mais valiosa, por um lado o imperador conseguiu assegurar sua superioridade e precedência pelo menos simbólica; e por outro a França comemorou a equiparação com o imperador. A relação entre hierarquia e igualdade dos Estados soberanos europeus no Congresso de Vestfália era complexa, às vezes equívoca e contraditória (Cardim, 2004).

Outro exemplo: as disputas tradicionais entre os diplomatas franceses e espanhóis pela precedência prejudicaram muito o avanço das negociações em Münster e Osnabrück. Essas controvérsias remontaram ao século XVI. Naquela época, Carlos I, rei de Aragão e Castela a partir de 1516, após assumir a re- 
gência de sua mãe Joana (1479-155), incapaz de governar, foi eleito, em 1519, também imperador do Sacro Império Romano-Germânico com o nome Carlos V, reunindo assim em si duas dignidades. Diante dessas circunstâncias, representantes da França concordaram em aceitar o direito da Coroa Espanhola à precedência no cerimonial. Após Carlos ter renunciado - em $1555 \mathrm{em}$ segredo, publicamente em 1558 - como imperador e rei, a Coroa Francesa começou de novo a contestar a precedência espanhola. No Congresso de Vestfália, as duas delegações, cada uma delas preparada para o conflito por suas instruções, combinaram reuniões alternadas em seus alojamentos; o local do início foi determinado por sorteio, o que não criou nenhuma precedência cerimonial, garantindo-se uma igualdade formal entre as duas coroas (May, 2016, pp. 94-110).

Um fator relevante na concorrência entre os Estados pré-modernos, ocorrido, no Congresso de Vestfália, pelo reconhecimento mútuo no palco diplomático, foi a figura do diplomata, condicionada por sua categoria específica, por sua qualidade de nobreza e pelo soberano e Estado representados. Apesar das formas convencionais e das tradições de protocolo existentes, o enorme número de diplomatas reunidos no congresso fez necessário se ajustarem e adaptarem os modelos conhecidos (Wilson, 2017, p. 778); desenvolveu-se, portanto, uma dinâmica própria.

Em vez da hierarquia medieval, empregou-se, à primeira vista, novas formas mais simples de trato mútuo. Concedeu-se aos monarcas o título de majestade. Já aos enviados de príncipes ou príncipes eleitores coube o título de excelência, lhes sendo concedido também o direito de terem uma carruagem com três parelhas ou seis cavalos. Realizou-se, por outro lado, na prática do congresso, uma (re)organização das relações diplomáticas internacionais. Os diplomatas reunidos no congresso chegaram, num processo moroso de negociação, em que cada um dos enviados justificou seu direito específico de honra por diferentes casos de precedência no passado, a um sistema que incluiu todos os atores envolvidos, mas não deixou, totalmente, os princípios de uma hierarquia (May, 2016, p. 89).

\section{CONSIDERAÇÕES FINAIS}

Os processos de transformação ocorridos a partir da Idade Média tardia, que se manifestaram em várias áreas da vida humana, referiram-se também aos Estados, às relações internacionais e à diplomacia moderna.

Os Estados começaram a expandir suas funções, concentrar as competên- 
cias nos respectivos governos, fortalecer os poderes soberanos, estabelecer um sistema administrativo e burocrático e racionalizar os procedimentos. Nas relações entre os Estados e os povos, podemos verificar transformações semelhantes, resultando na estabilização e na consolidação do sistema de Estados - apesar de todo o belicismo da época moderna (Asbach; Schröder, 2010). Os contatos esporádicos entre civilizações, culturas e Estados, que já haviam existido antes, começaram a aumentar, tornando-se mais frequentes e regulares. Diplomatas do século XVII precisavam de outras qualificações para além daquelas necessárias nos séculos XV e XVI: conhecimentos (pelo menos básicos) sobre a política interna e externa do próprio Estado e do Estado anfitrião, competências no cerimonial e na representação, proficiência de línguas e experiências na conduta nas cortes e nas sociedades de corte. Ou seja, um futuro diplomata necessitava de uma boa formação ou qualificação, seja em academias ou em universidades, seja no âmbito de uma profissionalização profunda e abrangente. As diversas transformações resultaram num novo padrão político-diplomático em meados do século XVII.

O Congresso de Vestfália é considerado um ponto de transição na configuração dos Estados pré-modernos, nas relações internacionais e na diplomacia, em que foram formados novos fundamentos de referência, no que diz respeito à organização do Estado, à (re)estruturação das relações internacionais e à prática da diplomacia. De fato, a Paz de Vestfália, considerada uma lei fundamental da Europa (ius publicum europaeum), tornou-se um referencial para o futuro, corroborado, literalmente, em vários tratados de paz acordados nos tempos depois de 1648: em Nimega (1678/1679), em Risvique (1697) ou em Utrecht, Baden e Rastatt (1712-1714). O ano de 1648 tornou-se um marco decisivo na história moderna.

O processo de diferenciação, em andamento desde o século XV, intensificou-se no Congresso de Vestfália, provocando embates, conflitos e crises diplomáticas. A fim de se resolverem as disputas e rivalidades pela precedência e pelo cerimonial, foram experimentadas, em Münster e Osnabrück, soluções variadas e criativas, com maior ou menor sucesso. A partir daí desenvolveu-se um sistema no qual cada Estados encontrou sua posição específica no sistema nascente dos Estados europeus. Foi alcançado um novo patamar em relação ao Estado pré-moderno e às relações diplomáticas entre eles.

Ainda não estava definida a questão das qualidades jurídicas e formais necessárias a um diplomata oficial nas negociações de paz. As diferenças entre a França e a Espanha nesta questão atrasaram muito as negociações e prejudicaram as relações políticas entre as duas coroas, impedindo, finalmente, até 
um acordo de paz entre elas (May, 2016, pp. 94-110; Rohrschneider, 2007). As lutas entre os dois poderes europeus continuaram até que a Paz dos Pirineus (1659) pôs fim à guerra por hegemonia.

A figura do "ambassadeur extraordinaire et plénipotenciaire" (embaixador extraordinário e plenipotenciário), que combinou as funções de (1) representar a dignidade do soberano (dignitas) e (2) assumir os plenos poderes do soberano ausente (potestas), foi um outro resultado das negociações de Paz de Vestfália (May, 2016, p. 121). Além disso, todo o quadro diplomático passou, durante o Congresso de Vestfália, por um processo de formação. Com isso, os direitos e privilégios dos enviados principais e secundários, assim como dos residentes, que pertenciam à segunda categoria, foram definidos de forma mais nítida ao longo do processo. Como exemplo, pode-se citar o caso das delegações dos príncipes eleitores: seus diplomatas foram admitidos ao congresso como atores do Direito Internacional aparentemente iguais, mas cuja posição jurídica oscilava, de fato, entre a plena soberania e a vassalagem feudal. Ao contrário das delegações dos Estados monárquicos e republicanos, seus enviados subalternos não foram equiparados, quanto ao cerimonial diplomático, aos enviados principais - uma forma acessória, mas óbvia, de se manter uma distinção cerimonial na hierarquia dos Estados soberanos e da diplomacia.

Desenvolveu-se em Münster e Osnabrück um sistema refinado e variado de símbolos, sinais e códigos em níveis diferentes ou paralelos, nem sempre reconhecidos por todos os participantes. Esse sistema visava conciliar a hierarquia tradicional entre os Estados com a pretensão a uma certa igualdade no palco diplomático - defendida, perseverante e obstinadamente, pelos representantes dos Estados menores e das repúblicas, ou seja, pelos "atores precários” (May, 2016, pp. 173-212). Estes pretenderam - às vezes com o argumento da soberania, às vezes não - se igualar às monarquias poderosas. A República de Veneza e a República das Sete Províncias Unidas dos Países Baixos tiveram sucesso, enquanto os príncipes eleitores (alemães) falharam nessa tentativa.

\section{REFERÊNCIAS}

ANDERSON, Matthew Smith. The Rise of Modern Diplomacy 1450-1919. London: Longman, 1993.

ASBACH, Olaf; SCHRÖDER, Peter (Orgs.). War, the State and International Law in Seventeenth-Century Europe. London: Routledge, 2010. 
AUTRAND, Françoise; ALLAIN, Jean-Claude (Orgs.). Histoire de la diplomatie française: Du Moyen Âge à l'Empire. Vol. 1. Paris: Perrin, 2007.

AZZOLINI, Monica; LAZZARINI, Isabella (Orgs.). Italian Renaissance Diplomacy: a sourcebook. Durham; Toronto: Pontifical Institute of Medieval Studies, 2017.

BALLESTRIN, Luciana. América Latina e o giro decolonial. Revista Brasileira de Ciência Política, Brasília, n. 11, pp. 89-117, 2013.

BEHRINGER, Wolfgang. Thurn und Taxis: die Geschichte der Post und ihrer Unternehmen. München: Piper, 1990.

BÉLY, Lucien. Lart de la paix en Europe: naissance de la diplomatie moderne, XVIe-XVIIIe siècle. Paris: Presses Univ. de France, 2008.

BÉLY, Lucien; RICHEFORT, Isabelle (Orgs.). L’Europe des Traités de Westphalie: Esprit de la Diplomatie et Diplomatie de l'Esprit. Paris: Presses Universitaires de France, 2000.

BIEBERSTEIN, Klaus. Der Gesandtenaustausch zwischen Karl dem Großen und Hārū ar-Rašīd und seine Bedeutung für die Kirche Jerusalems. Zeitschrift des Deutschen Palästina-Vereins, v. 109, n. 2, pp. 152-173, 1993.

BRANDÃO, Antônio Jackson de Souza. Jul. 2012. A Guerra dos Trinta Anos: imagens de um período de transição. Revista Acadêmica, ano 4. Disponível em: https://www. researchgate.net/publication/309619698_A_GUERRA_DOS_TRINTA_ANOS_ IMAGENS_DE_UM_PERIODO_DE_TRANSICAO. Acesso em: 3 jan. 2021.

BRUNNER, Otto. Land und Herrschaft: Grundfragen der territorialen Verfassungsgeschichte Österreichs im Mittelalter. Reimpressão da 5a Ed. de 1965. Darmstadt: Wissenschaftliche Buchgesellschaft, 1984 [1939].

BUENO, Elen de Paula; FREIRE, Marina; OLIVEIRA, Victor Arruda Pereira de. As origens históricas da diplomacia e a evolução do conceito de proteção diplomática dos nacionais. Anuario Mexicano de Derecho Internacional, v. 17, pp. 623-649, 2017.

CARDIM, Pedro. A prática diplomática na Europa do Antigo Regime. In: RODRIGUES, Luís Nuno; MARTINS, Fernando (Orgs.). História e Relações Internacionais. Évora: Publicações do Cidehus, Edições Colibri, 2004. pp. 11-53.

CARLETTI, Anna. A diplomacia da Santa Sé: suas origens e sua relevância no atual cenário internacional. Diálogo, Canoas, n. 16, pp. 31-55, 2010.

DANDELET, Thomas James; MARINO, John A. (Orgs.). Spain in Italy: Politics, Society, and Religion 1500-1700. Leiden; Boston: Brill, 2007.

DIGNAS, Beate; WINTER, Engelbert. Rome and Persia in late antiquity: Neighbours and Rivals. Cambridge: University Press, 2007.

DUCHHARDT, Heinz (Org.). Der Westfälische Friede. Historische Zeitschrift. Beihefte. Vol. 26. München: R. Oldenbourg, 1998.

ELLIOTT, John H. La Europa dividida. 1559-1598. Madrid: Siglo XXI de España Editores, S. A., 2015. 
FLETCHER, Catherine. Diplomacy in Renaissance Rome: The Rise of the Resident Ambassador. Cambridge: University Press, 2015.

FRIGO, Daniela (Org.). Politics and Diplomacy in Early Modern Italy: The Structure of Diplomatic Practice, 1450-1800. Cambridge: University Press, 2000.

GLEASON, Elisabeth G. Gaspar Contarini: Venice, Rome, and Reform. Berkeley: University of California Press, 1993.

GREENGRASS, Mark. Das verlorene Paradies: Europa 1517-1648. Darmstadt: Wisse nschaftliche Buchgesellschaft, 2018 [2014].

GREINDL, Gabriele. Die bayerischen Diplomaten auf dem Westfälischen Friedenskongress. Akademie aktuell, n. 49, v. 2, pp. 57-61, 2014.

GROTIUS, Hugo. On the Law of War and Peace. Ed. By Stephen C. Neff, Cambridge: University Press, 2012 [1625].

HEINEMEYER, Christian. Zwischen Reich und Region im Spätmittelalter: Governance und politische Netzwerke um Kaiser Friedrich III und Kurfürst Albrecht Achilles von Brandenburg (Historische Forschungen 108). Berlin: Duncker \& Humblot, 2016.

HOLLEGGER, Manfred. Anlassgesandtschaften - Ständige Gesandtschaften - Sondergesandtschaften: Das Gesandtschaftswesen in der Zeit Maximilians I. In: DÜNNEBEIL, Sonja (Org.). Außenpolitisches Handeln im ausgehenden Mittelalter: Akteure und Ziele. Wien: Böhlau, 2007. pp. 213-226.

JASPERT, Nikolas; KOLDITZ, Sebastian. Christlich-muslimische Außenbeziehungen im Mittelmeerraum: zur räumlichen und religiösen Dimension mittelalterlicher Diplomatie. Zeitschrift für Historische Forschung, v. 41, n. 1, pp. 1-88, 2014.

JELLINEK, Georg. Allgemeine Staatslehre. Berlin: Verlag O. Häring, 1905 [1900].

JUCKER, Michael; KINTZINGER, Martin; SCHWINGES, Rainer Christoph (Orgs.). Rechtsformen internationaler Politik: Theorie, Norm und Praxis vom 12. bis 18. Jahrhundert (Zeitschrift für Historische Forschung. Beihefte. Bd. 46). Berlin: Duncker \& Humblot, 2011.

KOHLER, Alfred. Expansion und Hegemonie 1450-1559 (Handbuch der Geschichte der Internationalen Beziehungen. Bd. 1). Paderborn; München; Wien; Zürich: Ferdinand Schöningh, 2008.

KOLLER, Alexander. Imperator und Pontifex: Forschungen zum Verhältnis von Kaiserhof und römischer Kurie im Zeitalter der Konfessionalisierung (1555-1648). Münster: Aschendorff, 2012.

LIMA, Douglas Mota Xavier de. Novos olhares sobre a diplomacia medieval. Transversos, Rio de Janeiro, v. 3, n. 3, pp. 77-91, 2015.

LIZIERO, Leonam Baesso da Silva. Algumas considerações sobre a influência do pensamento de Hugo Grotius no Direito Internacional contemporâneo. Quaestio Iuris, Rio de Janeiro, v. 8, n. 1, pp. 81-105, 2015. 
LYNCH, John. Spain 1516-1598: From Nation State to World Empire. Oxford: Blackwell, 1994.

MAINKA, Peter Johann. A luta europeia entre as dinastias dos Habsburgos e dos Valois pela Borgonha e Itália (1477-1559). História Questões \& Debates, Curitiba, v. 38, n. 1, pp. 185-224, 2003.

MAINKA, Peter Johann. O Sacro Império Romano-Germânico: um irregulare aliquod corpus et monstro simile? Diálogos, Maringá, v. 23, n. 2, pp. 162-184, 2019.

MAMOUN, Fansa (Org.). Kaiser Friedrich II (1194-1250): Welt und Kultur des Mittelmeerraums. Mainz: Zabern, 2008.

MARQUES, Adhemar; BERUTTI, Flávio; FARIA, Ricardo (Orgs.). História moderna através de textos. 12a Ed. São Paulo: Contexto, 2017 [1989].

MAY, Niels F. Zwischen fürstlicher Repräsentation und adliger Statuspolitik: Das Kongresszeremoniell bei den westfälischen Friedensverhandlungen (Beihefte der Francia. Bd. 82). Ostfildern: Thorbecke Verlag, 2016.

METZIG, Gregor M. Kommunikation und Konfrontation: Diplomatie und Gesandtschaftswesen Kaiser Maximilians I (1486-1519). Berlin: De Gruyter, 2016.

MOITA, Luís. Da diplomacia clássica à nova diplomacia. Janus 2006. Disponível em: http://www.janusonline.pt/arquivo/2006/2006_3_a.html. Acesso em: 3 jan. 2021.

MÜNKLER, Herfried; MÜNKLER, Marina. Lexikon der Renaissance. München: C. H. Beck, 2005 [2000].

MULSOW, Martin; ROUS, Anne-Simone (Orgs.). Geheime Post: Kryptologie und Steganographie der diplomatischen Korrespondenz europäischer Höfe während der Frühen Neuzeit (Historische Forschungen. Bd. 106). Berlin: Duncker \& Humblot, 2015.

OCHOA BRUN, Miguel Angel. Historia de la diplomacia española: La diplomacia de Carlos V. Madrid: Ministério de Asuntos Exteriores, 1991.

PRODI, Paolo. The Papal Prince: One Body and Two Souls: The Papal Monarchy in Early Modern Europe, Cambridge: University Press, 1982.

REINHARD, Wolfgang. Geschichte der Staatsgewalt: Eine vergleichende Verfassungsgeschichte Europas von den Anfängen bis zur Gegenwart. $3^{\mathrm{a}}$ Ed. München: Verlag C. H. Beck, 2002 [1999].

RODRÍGUEZ, Manuel Rivero. Diplomacia y Relaciones Exteriores en la Edad Moderna: 1453-1794. Madrid: Alianza, 2000.

ROHRSCHNEIDER, Michael. Der gescheiterte Frieden von Münster: Spaniens Ringen mit Frankreich auf dem Westfälischen Friedenskongtress (1643-1649). Münster: Aschendorff Verlag, 2007.

SANTOS, Boaventura de Sousa; MENESES, Maria Paula (Orgs.). Epistemologias do Sul. Coimbra: Almedina, 2009. 
SCHILLING, Heinz. Konfessionalisierung und Staatsinteressen 1559-1660 (Handbuch der Geschichte der Internationalen Beziehungen. Bd. 2). Paderborn; München; Wien; Zürich: Ferdinand Schöningh Verlag, 2007.

SCHLUCHTER, Wolfgang. O desencantamento do mundo: a visão do moderno em Max Weber. Rio de Janeiro: Editora da UFRJ, 2013 [2009].

TRILLO, Antonio; ECHEVARRÍA BACIGALUPE, Miguel Ángel (Orgs.). Geschichte des Aufstandes und der Kriege in den Niederlanden: Historia de la rebelión y guerra de Flandes (Studien für Geschichte der iberischen und iberoamerikanischen Länder). Vol. 11. Wien: Verlag für Geschichte und Politik; München: R. Oldenbourg Verlag, 2008.

VITÓRIA, Francisco de. Vorlesungen (Relectiones): Völkerrecht, Politik, Kirche. Vol. 1. Stuttgart et al.: Verlag W. Kohlhammer, 1995.

VITÓRIA, Francisco de. Vorlesungen (Relectiones): Völkerrecht, Politik, Kirche. Vol. 2. Stuttgart et al.: Verlag W. Kohlhammer, 1997.

WILSON, Peter H. Der Dreißigjährige Krieg: Eie europäische Tragödie. Darmstadt: Theiss; Wissenschaftliche Buchgesellschaft, 2017 [2009].

ZEY, Claudia (Org.). Aus der Frühzeit europäischer Diplomatie: zum geistlichen und weltlichen Gesandtschaftswesen vom 12: bis zum 15. Jahrhundert; Zürich: Chronos, 2008.

ZIEGLER, Karl-Heinz. The Peace Treaties of the Ottoman Empire with European Christian Powers. In: RANDALL, Lesaffer (Org.). Peace Treaties and International Law in European History. Cambridge: University Press, 2004. pp. 338-361.

Artigo submetido em 5 de janeiro de 2021.

Aprovado em 17 de agosto de 2021.

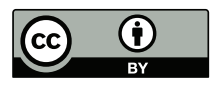

